University of Wollongong

Research Online

Faculty of Engineering and Information

Faculty of Engineering and Information

Sciences - Papers: Part A

Sciences

2017

\title{
Predicting concentrations of fine particles in enclosed vessels using a camera based system and CFD simulations
}

L Lulbadda Waduge

University of Greenwich

S Zigan

University of Greenwich

Luke Stone

University of Wollongong, les019@uowmail.edu.au

A Belaidi

University of Greenwich

P Garcia-Trinanes

University of Greenwich

Follow this and additional works at: https://ro.uow.edu.au/eispapers

Part of the Engineering Commons, and the Science and Technology Studies Commons

Research Online is the open access institutional repository for the University of Wollongong. For further information contact the UOW Library: research-pubs@uow.edu.au 


\title{
Predicting concentrations of fine particles in enclosed vessels using a camera based system and CFD simulations
}

\author{
Abstract \\ One of the main challenges in industries handling biomass is the consequence of the particle breakage of \\ pelletised biomass in smaller fractions which can lead to fine particles smaller $500 \mathrm{im}$ that can form dust \\ clouds in the handling and storing equipment. These dust clouds present potential health and safety \\ hazards as well as dust explosion hazards to plant operators because the airborne dust can occur in high \\ concentrations close to the dust explosion limits of the biomass material, during the filling process of \\ storage silos. Preventing dust explosions and the damage of plant infrastructures requires a profound \\ understanding of the particle/air dynamics in the dust cloud circulating in the storage silo. The limited \\ access to the storage facilities as well as the silo size requires a detailed study of the particle/air \\ dynamics at different scales. Lab scale experiments were conducted as a first step to establishing a new \\ optical method for measuring particle concentrations. A small scale experimental rig was fed centrally \\ with different sized wood pellets and a single camera and a laser was utilised to capture the dust \\ concentration in different areas of the silo. According to the experimental results, a higher mass \\ concentration of dust was observed near the silo wall as well as near the main particle jet. However, the \\ mass concentrations were below the explosive limits at the area in between main particle jet and silo \\ wall. These experimental results were then feeding into a 2D CFD simulation representing the particle \\ dynamics in the laser sheet (2D plane). Qualitative findings show a good agreement of the particle/air \\ dynamics between experiments and simulations.

\section{Disciplines} \\ Engineering | Science and Technology Studies

\section{Publication Details} \\ Lulbadda Waduge, L. L., Zigan, S., Stone, L. E., Belaidi, A. \& Garcia-Trinanes, P. (2017). Predicting \\ concentrations of fine particles in enclosed vessels using a camera based system and CFD simulations. \\ Process Safety and Environmental Protection, 105 262-273.
}




\title{
Predicting concentrations of fine particles in enclosed vessels using a camera based system and CFD simulations
}

\author{
L. L. Lulbadda Waduge ${ }^{\star}$, S. Zigan ${ }^{\dagger}$, Luke E. Stone $^{\star}$, A. Belaidi $^{\dagger}$ and P. García- \\ Triñanes*, \\ * The Wolfson Centre for Bulk Solids Handling Technology \\ ${ }^{\dagger}$ Department of Mechanical Manufacturing and Design Engineering \\ University of Greenwich, Central Avenue, Chatham Maritime, Kent ME4 4TB \\ - Faculty of Engineering and Information Sciences, University of Wollongong, Northfields \\ Avenue, Wollongong, N.S.W, 2522, Australia

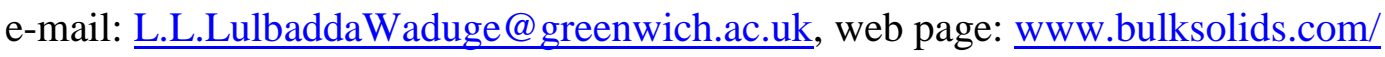 \\ e-mail: $\underline{\text { s.zigan@gre.ac.uk, e-mail: h.belaidi@greenwich.ac.uk, }}$ \\ e-mail: P.GarciaTrinanes@greenwich.ac.uk
}

\begin{abstract}
Biomass generates a increasing interest as renewable fuel and industries handling biomass show fast levels of growths over the last decade and, yet, several challenges remain in the handling, transporting and storing of biomass such as wood pellets. One challenge is the consequence of the particle breakage of pelletised biomass in smaller fractions which can lead to fine particles smaller 500 microns which can form dust clouds in the handling and storing equipment. These dust clouds present potential health and safety hazards as well as dust explosion hazards to plant operators because during the filling process of storage silos the airborne dust can occur in high concentrations close to the dust explosion limits of the
\end{abstract}


biomass material. Preventing dust explosions and the damage of plant infrastructures requires a profound understanding of the particle/ air dynamics in the dust cloud circulating in the storage silo. The limited access to the storage facilities as well as the silo size require a detailed study of the particle/ air dynamics at different scales. Lab scale experiments were conducted as a first step to establish a new optical method for measuring particle concentrations. A small scale experimental rig was fed centrally with different sized wood pellets and a single camera and a laser was utilised to capture the dust concentration in different areas of the silo. These experimental results were then feeding into a 2D CFD simulation representing the particle dynamics in the laser sheet (2D plane). Qualitative findings show a good agreement of the particle/ air dynamics between experiments and simulations.

\section{Keywords}

Laser, optical method, dust explosions, CFD, experimental, storage silos, particle dynamics

\section{Introduction}

Dust explosions are a major concern of industries handling combustible bulk materials containing fractions of fines (particles smaller than $355 \mu \mathrm{m}$ ). Dust explosion risks are present in many industries (e.g. power, chemical and food industries) handling wood and paper products, grain and flour, metal products or pulverized coal to mention just few (Frank 2004).

The consequences of dust explosions in industrial facilities can be severe for the work force and plant operators as such explosions can cause fatalities, injuries and facility damage e.g. to the storage silos (U.S. CSB 2010).

Dust explosions in storage silos occur in the presence of an ignition source capable of igniting an explosive fuel mixture atmosphere. In the presence of favourable conditions such as dust concentration and air turbulence levels inside the silo, explosions hazards are increased. When dust concentrations in the circulating air inside a closed vessel is within the range of around $300 \mathrm{~g} / \mathrm{m}^{3}$ to $1500 \mathrm{~g} / \mathrm{m}^{3}$ with a narrow particle size distribution (of between 10 to 40 microns) the highest propensity for dust explosions is present. The quantification of dust concentrations and particle size distributions in the atmosphere-fuel mixture in the storage silo can provide a baseline for evaluating dust explosions risks not only for storage silos but also for industrial facilities in general (Davis et al. 2011, p.839). 
The dust concentrations in silos depends on equipment parameters e.g. the operation mode of the silo (e.g. filling or emptying) and material parameters e.g. the natural variations of the particle size distribution in the material handled. Some materials, such as biomass/ wood pellets, tend to dust significantly.

The environmental parameters such as temperature and air humidity have to be added to the list of material and equipment parameters when evaluating the amount of airborne fines in storage silos. The large number of parameters influencing the concentration of airborne dust can cause variations of up to 30 percent between filling and discharge cycles. The large variations of dust concentrations with time in the industrial process require a detailed study of the particle settling behaviour which can be best studied using small scale experiments and simulation approaches such as Computational Fluid Dynamics (CFD). For verifying and validating CFD models the simulation results need to be compared with experimental data (Klippel et al. 2014). Researcher e.g. (Réthoré et al. 2014), (Wang et al. 2016) and (Krueger et al. 2015) suggest the use of optical methods such as using a single camera for measuring the settling of particles in a silo during the filling process and evaluating the particle displacements by correlating digital images. The displacement of fines following air currents in the silo can be estimated from the images as successive positions over time. Based on averaged images it is possible to track temporal dust evolutions in the silo. For the illumination of dust particles in a plane, a laser light source is recommended (Gouesbet et al. 2015).

This paper explores the possibility of verifying and validating CFD models using a bench scale dustiness tester and a single camera system with a laser source to illuminate particles.

\section{Materials and methods}

Wood pellets produced from compacted sawdust contain a wide particle size distribution (Oveisi et al. 2013). 


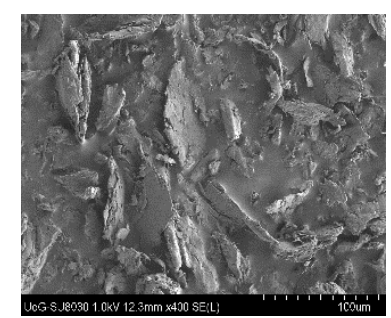

(a)

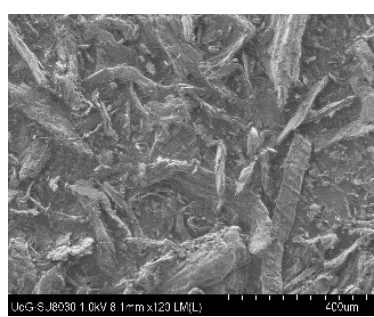

(b)

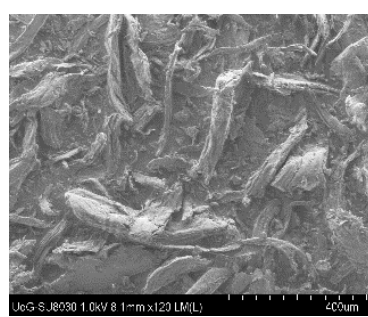

(c)

Figure 1: SEM (Scanning Electron Microscope) Images of wood dust samples with various sizes (a) size range from 60-90 $\mu \mathrm{m}(\mathrm{b})$ size range from 100-125 $\mu \mathrm{m}$ (c) size range from 300 to $355 \mu \mathrm{m}$

The wood pellets were sieved into different fractions. The coarser particle fractions had a particle size ranging from 3.15 to $4.75 \mathrm{~mm}$ (obtained from sieving the material with a Rotex ${ }^{\circledR}$ size analyser/ Apex screener (Allen 2003). The smaller particle fractions passed a sieve of $500 \mu \mathrm{m}$. The fines (particles below $355 \mu \mathrm{m}$ ) are shown in Figure 1. The coarse and small size particle fractions are shown in Figure 2. The material used in the experiments had a mass ratio of coarse to fine material of 10:1.

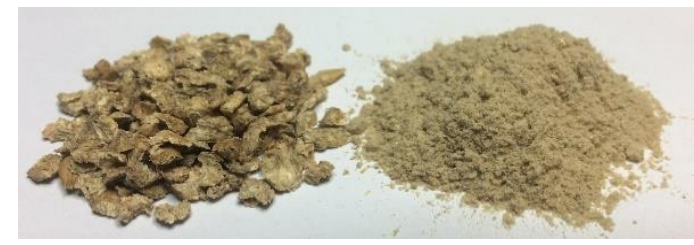

(a)

(b)

Figure 2: The material used in the experiment is a mixture of coarse (a) and fine (b) particles mixed with the mass ratio of 10:1.

The material used in the experiments was investigated further as the CFD simulation setup required more data for input parameters. Fines were prepared through sieving wood pellet dust through a 355 and then a 63 micron sieve before being analysed in a Gradex sieve system. A sample of the coarse particles ( 3.15 to $4.75 \mathrm{~mm}$ ) was prepared by mixing fines in a ratio of 10 grams of coarse material to 1 gram of fine material to obtain the same mixture used in the silo experiments. These samples were used to develop a Rosin Rammler distribution and to calculate the average particle density. Using the Rosin Rammler fitting method the mean diameter was calculated to be 134.3 microns and the average spread parameter was determined to be 1.93. Figure 3 shows a comparison of the sieve distribution to the Rosin Rammler calculated distribution. 
PARTICLE DISTRIBUTION

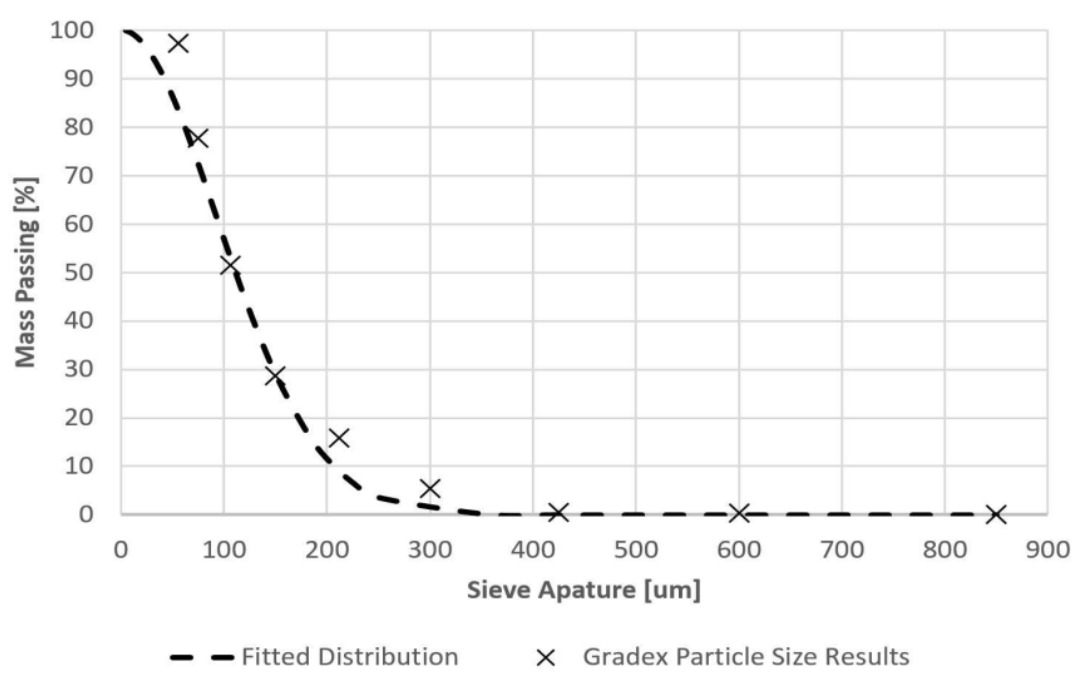

Figure 3: Rosin Rammler Distribution Fitted to Sieve Particle Size Results

After conducting density measurements using a pycnometer the level of compressibility of the material is demonstrated through differences in calculated densities. This variation is due to the material having a cellular nature, which causes porosity in the particles; at high pressures, these pores are compressed leading to a lower volume occupied by the material and therefore a decrease in calculated density. For the simulation, the lower density of 1460 $\mathrm{kg} / \mathrm{m}^{3}$ was used for fine and coarse materials.

\section{Experimental set up}

Wood pellets were fed centrally at a flowrate of $(82 \mathrm{~g} / \mathrm{s})$ into a cylindrical silo of $1200 \mathrm{~mm} \mathrm{x}$ $400 \mathrm{~mm}$ (height $\mathrm{x}$ diameter) shown in Figure 4. The air was extracted at four extraction ports equally spaced on the top of the experimental silo and the flow rate of $0.04 \mathrm{l} / \mathrm{s}$ from each port matched the volumetric flow rate of air entering the silo during the filling process. The separation of fines from the main particle jet was examined at the end of the experiment by collecting the retained fines in different areas at the silo bottom.

A 500mW 532nm (bright green colour) laser (Coherent ${ }^{\circledR}$ DPSS 532) was used for creating a thin vertical light sheet. The vertical laser sheet was obtained by projecting a linear laser beam through a horizontal glass rod $8 \mathrm{~mm}$ in diameter. A Nikon D800E with Nikon AF-S NIKKOR 16-35mm lens was used to capture the video footage of the circulating dust in the experimental silo in a symmetry plane as shown in Figure 4. 


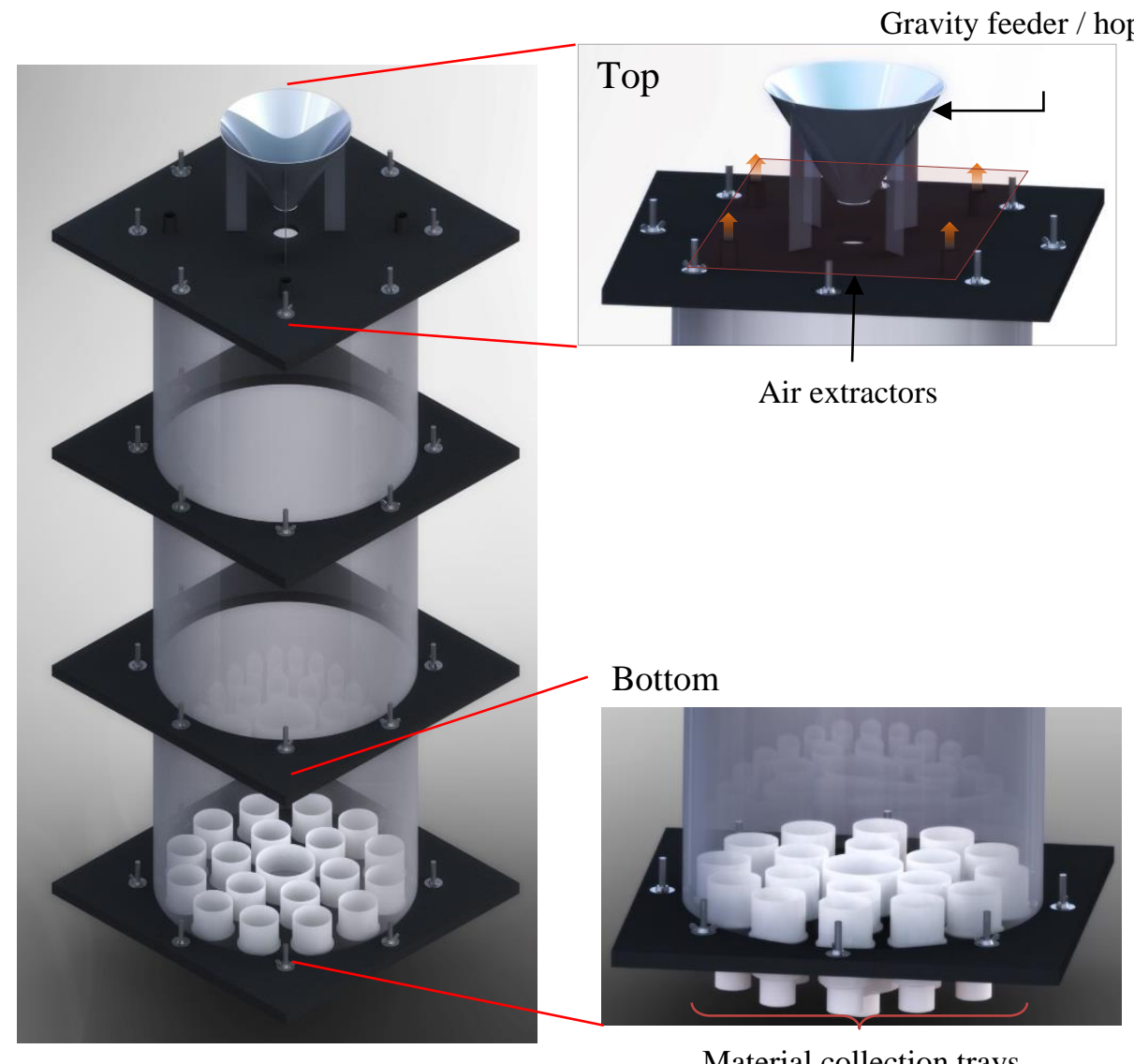

Material collection trays

Figure 4: Experimental silo of $1200 \mathrm{~mm} \times 400 \mathrm{~mm}(h \times d)$ with gravity feeder on the top and material collection compartments at the bottom

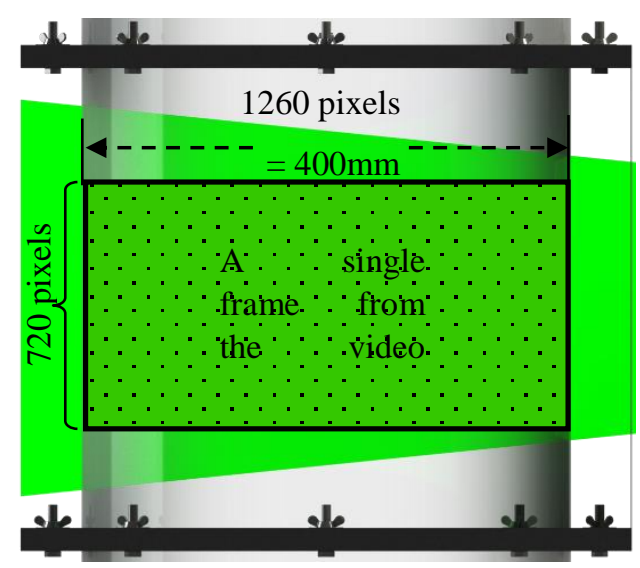

Figure 5: width of the video footage is 1260 pixels. And as the silo has a diameter of 400mm, that width of 1260 pixels is equal to $400 \mathrm{~mm}$; the width of a single pixel in video footage is $317.5 \mu \mathrm{m}$; as all the pixels are squares, the size of a pixel is $(317.5 \times 317.5) \mu \mathrm{m}$

The video footage was captured at 59 frames per second giving an effective resolution inside the silo of 1260 x 720 pixels. Specific areas of video frames spread across the silo's cross section were targeted to obtain particle concentration per surface area. The area covered by a single pixel in each video frame was $317.5 \times 317.5 \mu \mathrm{m}$ and the fine particles used in the 
experiments were between 60 to $355 \mu \mathrm{m}$. However, as some fines are much smaller than the pixel size, these fines create only a single shade of grey on the pixel as shown in figure 5 .

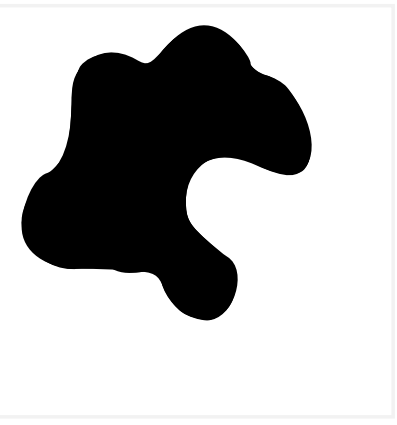

(a)

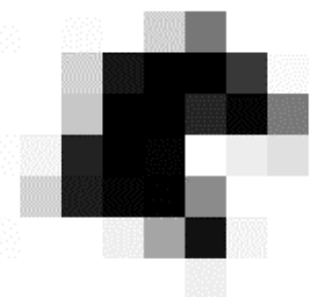

(b)

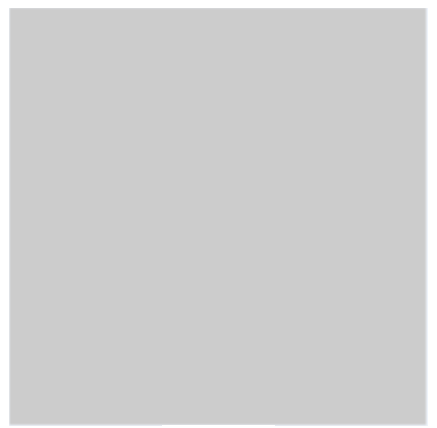

(c)

Figure 6: (a) actual shape of a particle $(200 \times 200 \mu \mathrm{m})$, (b) Same particle captured in a single pixel from high resolution image, (c) Same particle captured in a single pixel from low resolution video frame.

In the first stage in the methodology used, the level of brightness recorded in a single pixel was qualitatively related to the number/size distribution of particles in the pixel. Brightness was calibrated using a high resolution image as shown in Figure 7 (a). Since this image captured the number/size of particles and provided information on brightness, a relationship between brightness and the number of particles could be established. By assigning a corresponding shade of grey to the number of particles in a frame, the relationship was used to estimate the distribution of particles per average frame in the captured video footage. For the approach to be applicable, both the high resolution image and the video footage were taken at homogeneous conditions to ensure the same dynamic range for shades of grey were obtained. This can be linked to the number and size of particles captured in a single pixel of the video footage.

In the second stage, a quantitative relationship between the number/size of particles and the shade of grey on a pixel in a video frame was obtained. First, a Matlab® programme converted the high resolution image to a resolution similar to that of the video footage in order to relate particle sizes/number to specific shades of grey. Then the pixels in the converted image were re-mapped in to an image with "pseudo" colour pixels to make particle sizes/numbers easily identifiable. Table 1 below shows the assigned colours to the number/particle size. 


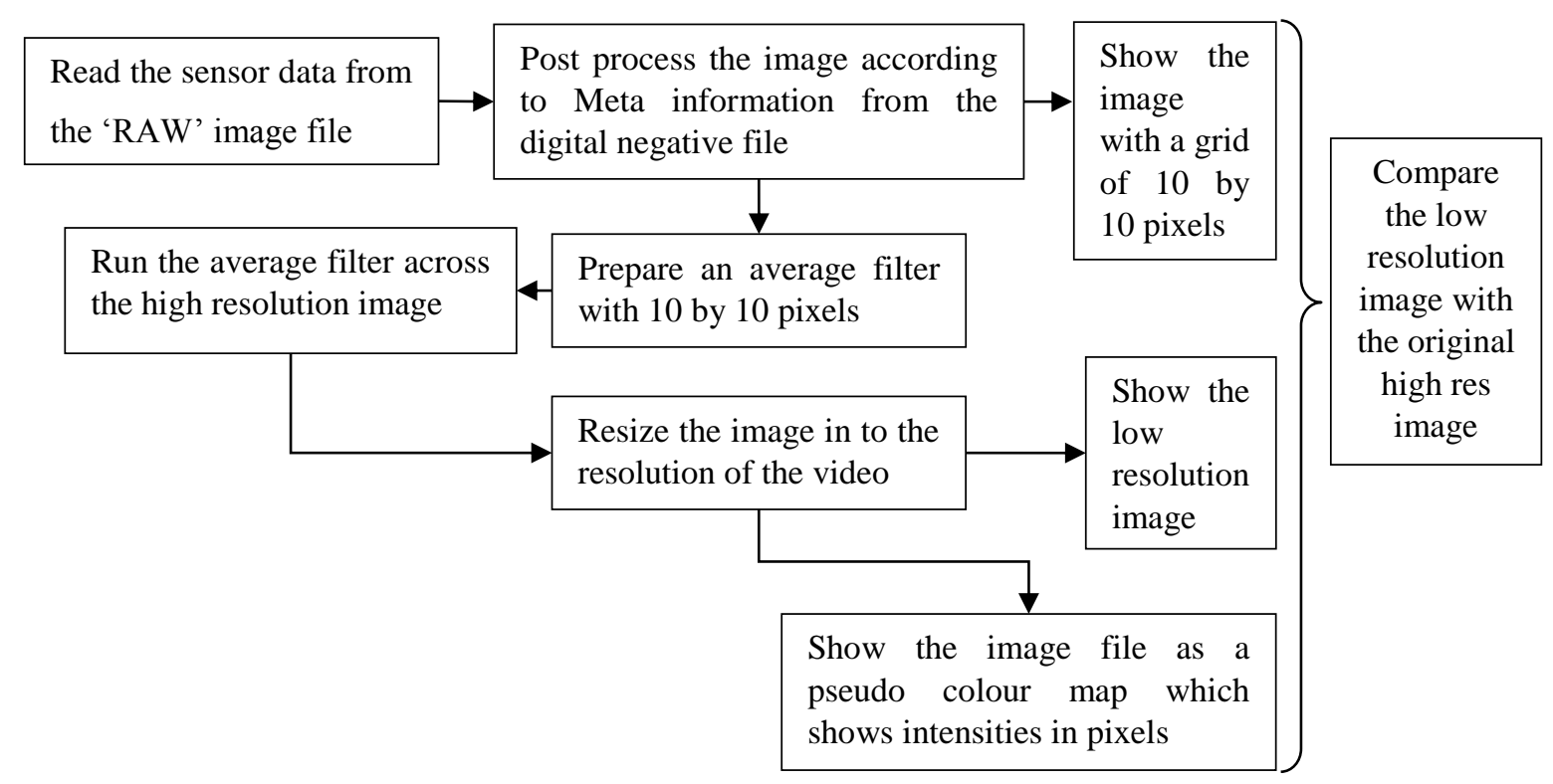

Figure 7 : Block diagram of the Matlab program

The number of particles counted within a unit square was divided by the volume formed by unit square area and the laser sheet thickness to obtain the volumetric particle concentration.

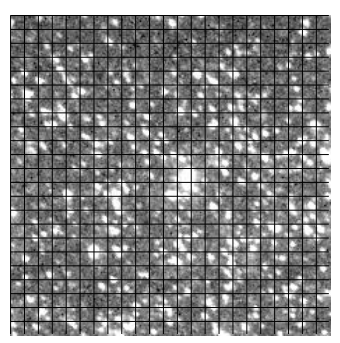

(a)

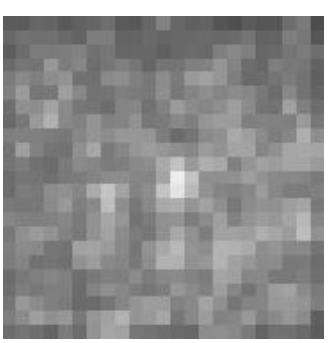

(b)

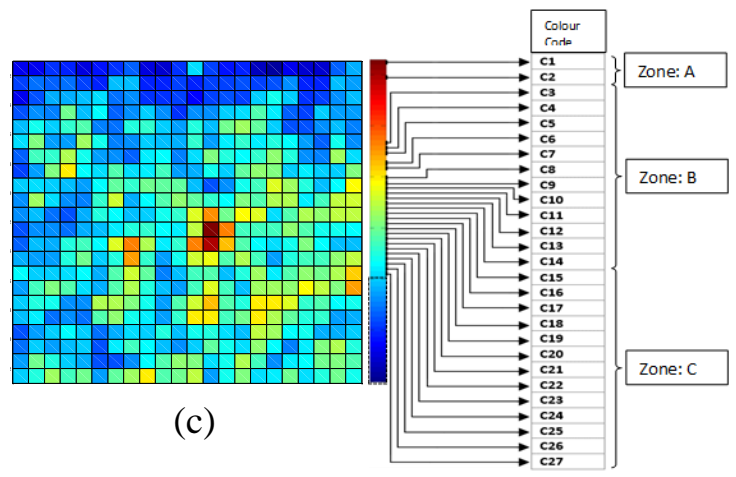

(d)

Figure 8: Comparison of resolution vs pixels sizes for a) high resolution image, b) video frame and c) and Matlab generated color map $(d)$ colour representation. 
Table 1: Number of particles represented by each shade of grey

\begin{tabular}{|c|c|c|c|}
\hline Particle sizes & Colour code & $\begin{array}{l}\text { Number of } \\
\text { particles per } \\
\text { low-res. pixel }\end{array}$ & $\begin{array}{l}\text { Concentration of particles (number of } \\
\text { particles per } \mathrm{m}^{3} \text { ) }\end{array}$ \\
\hline Large & c1 & 0.5978 & $5.9302 \mathrm{E}+08$ \\
\hline$(300 \mu \mathrm{m}-355 \mu \mathrm{m})$ & $\mathrm{c} 2$ & 0.5017 & $4.9769 \mathrm{E}+08$ \\
\hline Medium & c3 & 1.8044 & $1.7900 \mathrm{E}+09$ \\
\hline \multirow[t]{11}{*}{$(100 \mu \mathrm{m}-125 \mu \mathrm{m})$} & c4 & 1.8022 & $1.7878 \mathrm{E}+09$ \\
\hline & c5 & 1.7788 & $1.7646 \mathrm{E}+09$ \\
\hline & c6 & 1.7722 & $1.7580 \mathrm{E}+09$ \\
\hline & c7 & 1.7755 & $1.7613 \mathrm{E}+09$ \\
\hline & $\mathrm{c} 8$ & 1.7669 & $1.7528 \mathrm{E}+09$ \\
\hline & c9 & 1.7666 & $1.7525 \mathrm{E}+09$ \\
\hline & c10 & 1.7621 & $1.7480 \mathrm{E}+09$ \\
\hline & c11 & 1.7599 & $1.7458 \mathrm{E}+09$ \\
\hline & c12 & 1.7595 & $1.7454 \mathrm{E}+09$ \\
\hline & c13 & 1.7196 & $1.7058 \mathrm{E}+09$ \\
\hline & c14 & 1.6327 & $1.6196 \mathrm{E}+09$ \\
\hline Small & c15 & 3.3274 & $3.3008 \mathrm{E}+09$ \\
\hline \multirow[t]{12}{*}{$(63 \mu \mathrm{m}-90 \mu \mathrm{m})$} & c16 & 3.1211 & $3.0961 \mathrm{E}+09$ \\
\hline & c17 & 3.0938 & $3.0691 \mathrm{E}+09$ \\
\hline & c18 & 2.939 & $2.9155 E+09$ \\
\hline & c19 & 2.8949 & $2.8718 \mathrm{E}+09$ \\
\hline & c20 & 2.8949 & $2.8717 \mathrm{E}+09$ \\
\hline & c21 & 2.8622 & $2.8393 \mathrm{E}+09$ \\
\hline & c22 & 2.8563 & $2.8335 \mathrm{E}+09$ \\
\hline & c23 & 2.8554 & $2.8326 \mathrm{E}+09$ \\
\hline & c24 & 2.8528 & $2.8300 \mathrm{E}+09$ \\
\hline & c25 & 2.8516 & $2.8288 \mathrm{E}+09$ \\
\hline & c26 & 2.8473 & $2.8245 \mathrm{E}+09$ \\
\hline & c27 & 2.8415 & $2.8188 \mathrm{E}+09$ \\
\hline
\end{tabular}

The particle concentrations as shown in Table 1 are expressed as particle population per unit volume (number of particles per cubic metre). Since the standard unit for measuring fines/dust concentrations in industry is grams per cubic metre the obtained results presented in Table 1 need to be multiplied with an averaged mass of a single particle. Since the particle sizes varies significantly, the average mass of a particle was calculated using three different particle size fractions. Different SEM (scanning electron microscope) images were taken as shown in Figure 9. The number of particles were counted within the scanned area using a Matlab® programme. 


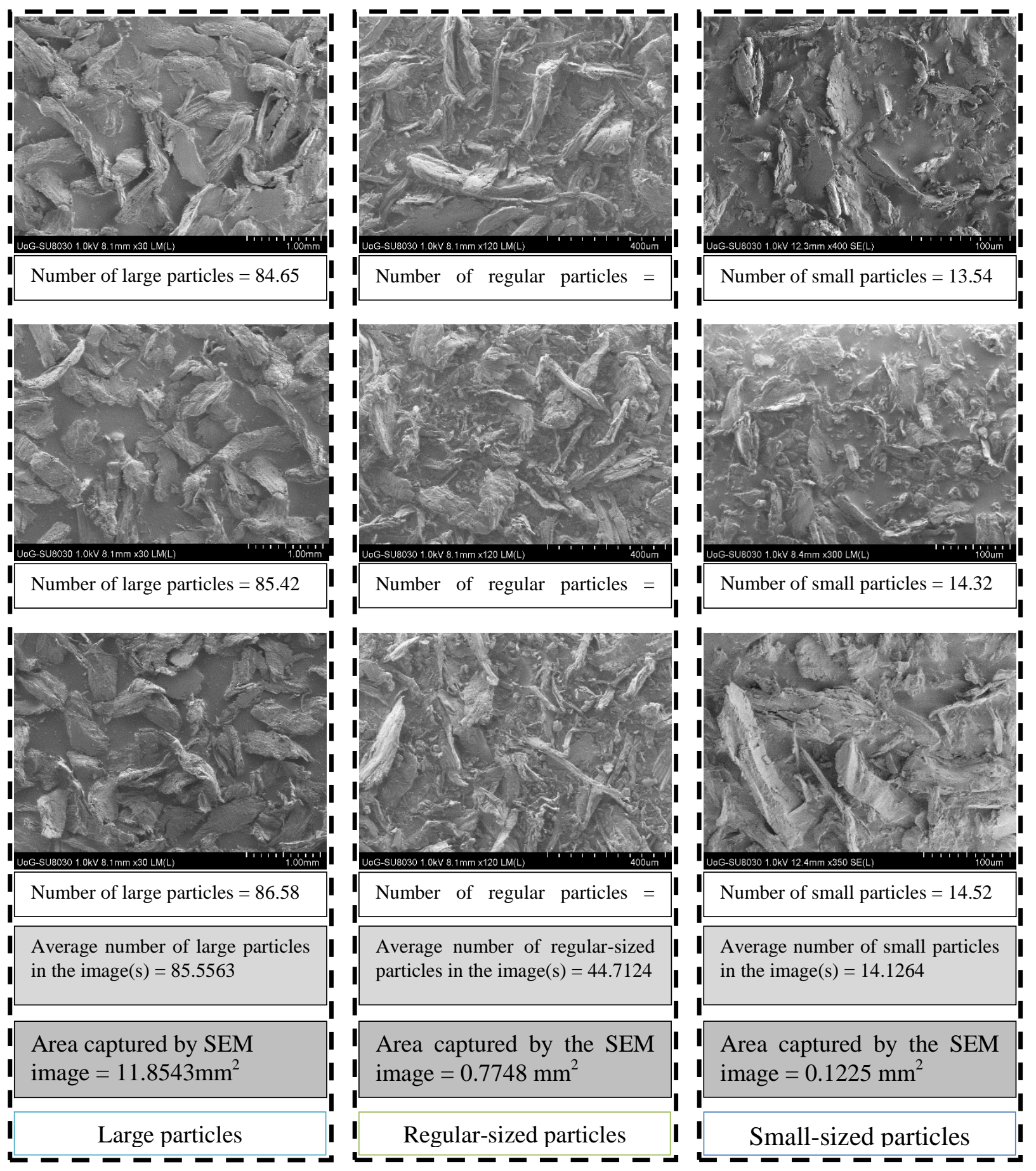

Figure 9: Number of wood particles measured per area using SEM 
Table 2 : Extrapolation for number of particles in $900 \mathrm{~mm}^{2}$.

\begin{tabular}{|l|c|c|c|c|c|}
\cline { 2 - 6 } \multicolumn{1}{c|}{} & $\begin{array}{c}\text { Area } \\
\text { measured } \\
\left(\mathrm{mm}^{2}\right)\end{array}$ & $\begin{array}{c}\text { Number } \\
\text { of } \\
\text { particles }\end{array}$ & $\begin{array}{c}\text { Number of } \\
\text { particles in } \\
900 \mathrm{~mm}^{2}\end{array}$ & $\begin{array}{c}\text { mass (total) of } \\
\text { each particle } \\
\text { types (in } \\
\left.900 \mathrm{~mm}^{2}\right)\end{array}$ & $\begin{array}{c}\text { Mass of a single } \\
\text { particle (in } \\
\text { grams) }\end{array}$ \\
\hline $\begin{array}{l}\text { Large-sized } \\
\text { particles }\end{array}$ & 11.85431840 & 85.5563 & 6495.5797 & $0.00575 \mathrm{~g}$ & $8.85217 \times 10^{-7}$ \\
\hline $\begin{array}{l}\text { regular-sized } \\
\text { particles }\end{array}$ & 0.77488362 & 44.7124 & 51931.8758 & $0.00422 \mathrm{~g}$ & $8.12603 \times 10^{-8}$ \\
\hline $\begin{array}{l}\text { small-sized } \\
\text { particles }\end{array}$ & 0.12246170 & 14.1264 & 103818.2518 & $0.00212 \mathrm{~g}$ & $2.04203 \times 10^{-8}$ \\
\hline
\end{tabular}

The masses of particles for the three different particle size fractions were estimated by using equation 1.

$M_{P s}=\frac{M_{\text {Total }}}{\left[\frac{N_{C A}}{A_{S E M}} \times A_{L}\right]}$

(Equation 1)

where $M_{P s}$ is the mass of a single particle, $M_{\text {Total }}$ is the total mass of all particles on a reference squared tape/layer $A_{L}=900 \mathrm{~mm}^{2}, N_{C A}$ is the number of particles within a captured area by SEM, $A_{S E M}$ is the captured area by SEM.

The particle average mass $\left(M_{P_{s}}\right)$ was obtained by using a reference sheet covered with a monolayer of particles at a given size fraction. $N_{C A}$ was then estimated using the SEM images which was then extrapolated to the reference area $A_{L}$. The total mass in $A_{L}$ was divided by $\mathrm{N}_{\mathrm{CA}}$ to obtain the average mass of a single particle. This was multiplied by particle numbers shown in Table 1 to obtain mass concentration per cubic metre as shown in Equation 2.

$$
P_{c}=M_{P s} \times N_{P V}
$$

(Equation 2)

where $P_{c}$ is the total mass per cubic metre and $N_{P V}$ represents the number of particles within the same volume. 
Table 3: Concentrations in grams per cubic metre.

\begin{tabular}{|c|c|c|}
\hline Particle sizes & Colour code & concentration of particles $\left(\mathrm{g} / \mathrm{m}^{3}\right)$ \\
\hline \multirow{2}{*}{$\begin{array}{c}\text { Large } \\
(300 \mu \mathrm{m}-355 \mu \mathrm{m})\end{array}$} & $\mathrm{C} 1$ & 524.9505 \\
\hline & $\mathrm{C} 2$ & 440.5615 \\
\hline \multirow{12}{*}{$\begin{array}{c}\text { Medium } \\
(100 \mu \mathrm{m}-125 \mu \mathrm{m})\end{array}$} & $\overline{\mathrm{C} 3}$ & 1455.4534 \\
\hline & $\mathrm{C} 4$ & 145.2760 \\
\hline & $\mathrm{C} 5$ & 143.3897 \\
\hline & C6 & 142.8577 \\
\hline & $\mathrm{C} 7$ & 143.1237 \\
\hline & $\mathrm{C} 8$ & 142.4305 \\
\hline & $\mathrm{C} 9$ & 142.4063 \\
\hline & $\mathrm{C} 10$ & 142.0436 \\
\hline & $\mathrm{C} 11$ & 141.8662 \\
\hline & $\mathrm{C} 12$ & 141.8340 \\
\hline & C13 & 138.6176 \\
\hline & $\mathrm{C} 14$ & 131.6126 \\
\hline \multirow{13}{*}{$\begin{array}{c}\text { Small } \\
(63 \mu \mathrm{m}-90 \mu \mathrm{m})\end{array}$} & C15 & 67.4031 \\
\hline & $\mathrm{C} 16$ & 63.2241 \\
\hline & $\mathrm{C} 17$ & 62.6710 \\
\hline & $\mathrm{C} 18$ & 59.5353 \\
\hline & C19 & 58.6429 \\
\hline & $\mathrm{C} 20$ & 58.6419 \\
\hline & $\mathrm{C} 21$ & 57.9795 \\
\hline & $\mathrm{C} 22$ & 57.8600 \\
\hline & $\mathrm{C} 23$ & 57.8418 \\
\hline & $\mathrm{C} 24$ & 57.7891 \\
\hline & $\mathrm{C} 25$ & 57.7648 \\
\hline & $\mathrm{C} 26$ & 57.6777 \\
\hline & $\mathrm{C} 27$ & 57.5602 \\
\hline
\end{tabular}

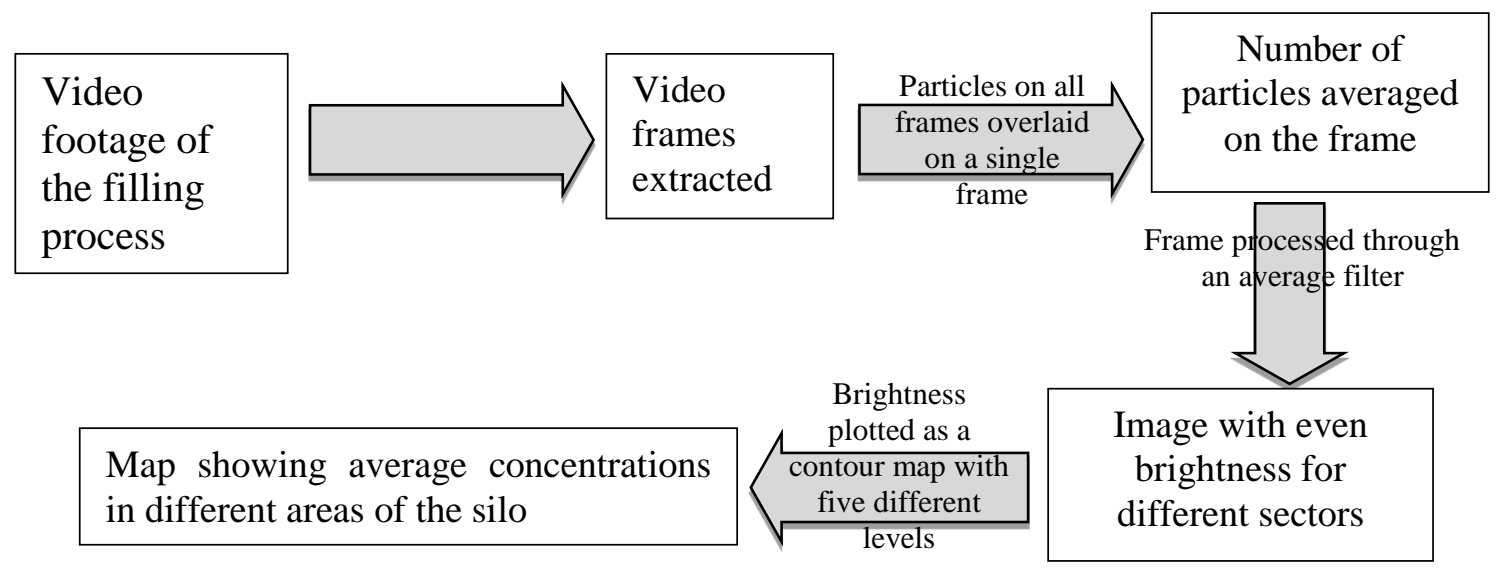

Figure 10: Block diagram of the process steps for generating the dust concentration contour maps in Matlab® 
Video frames were captured over a period of time and superimposed to provide enough data sets for image analysis. The frames were analysed using the Matlab® program as shown in Figure 10. Then a contour map was established to show the different levels of dust concentration. In the final step, levels of brightness were identified and matched with the data obtained in table 3 to show the dust distribution in grams per cubic meter.

\section{Simulation setup}

CFD was coupled with the Discrete Element Method (DEM) in the commercial software package ANSYS/ Fluent (Package) to predict particle concentrations in a 2D plane (similar to the laser sheet) in the experimental set up. The obtained particle concentrations were then qualitatively verified by direct comparison with results obtained from the optical measurements in the experimental silo.

As the case study is a comparison to the laser sheet a 2D simulation was sufficient for a direct comparison, additionally, it is assumed that the flow is symmetric and therefore only half of the silo is required for this simulation. After developing the 2D geometry, the mesh was calculated. To ensure that the results are independent of the mesh; a sensitivity study was undertaken. The study revealed that the overall appearance of the velocity profile inside the silo stayed the same and that only a small variance in the maximum velocity was observed. Finally, due to the small variance between the two finest meshes a mesh size of 38402 elements was used for the final simulation. The results of this study are outlined in Table 4.

Table 4: Mesh Sensitivity Results

\begin{tabular}{|l|c|c|c|c|}
\hline $\begin{array}{l}\text { Mesh } \\
\text { Parameters }\end{array}$ & $\begin{array}{c}\text { Coarse } \\
{[\mathbf{1 0} \mathbf{~ m m}]}\end{array}$ & $\begin{array}{c}\text { Medium } \\
{[\mathbf{5} \mathbf{~ m m}]}\end{array}$ & $\begin{array}{c}\text { Fine } \\
{[\mathbf{2 . 5} \mathbf{~ m m}]}\end{array}$ & $\begin{array}{c}\text { Very Fine } \\
{[\mathbf{1 . 5} \mathbf{~ m m}]}\end{array}$ \\
\hline Elements & 2400 & 9623 & $\mathbf{3 8 4 0 2}$ & 106569 \\
\hline $\begin{array}{l}\text { Simulation } \\
\text { Duration }\end{array}$ & $1 \mathrm{hr} 14$ minutes & $1 \mathrm{hr} 50 \mathrm{mins}$ & $\mathbf{3 ~ h r ~ 6 ~ m i n u t e s}$ & $6 \mathrm{hr} 40 \mathrm{mins}$ \\
\hline $\begin{array}{l}\text { Maximum } \\
\text { Velocity }\end{array}$ & $0.954 \mathrm{~m} / \mathrm{s}$ & $0.893 \mathrm{~m} / \mathrm{s}$ & $\mathbf{0 . 8 4 4} \mathbf{~ m} / \mathbf{s}$ & $0.848 \mathrm{~m} / \mathrm{s}$ \\
\hline $\begin{array}{l}\text { Error (Relative } \\
\text { to Finest Mesh) }\end{array}$ & $12.50 \%$ & $5.31 \%$ & $\mathbf{0 . 4 7 \%}$ & $0 \%$ \\
\hline
\end{tabular}




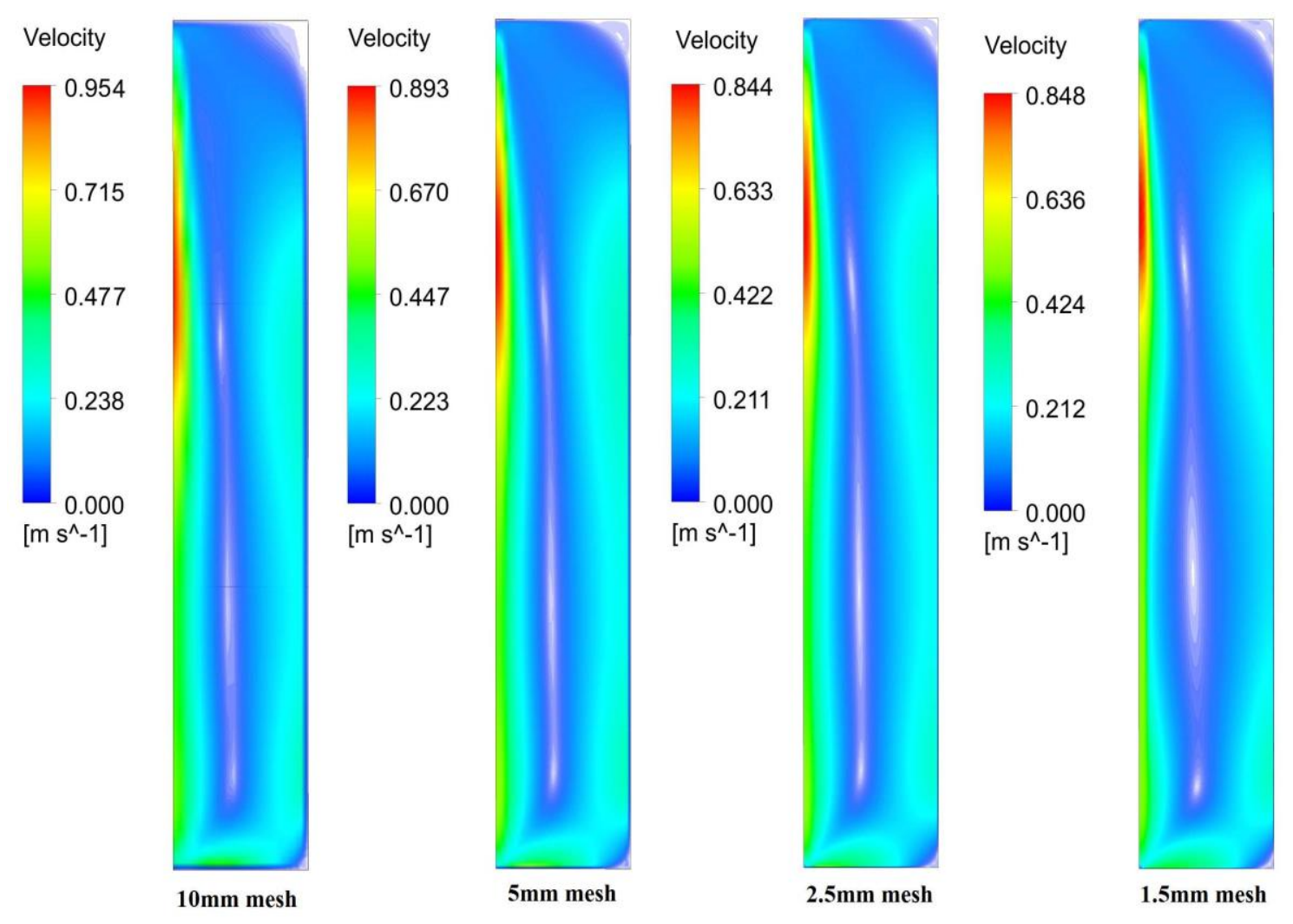

Figure 11: Velocity profiles for each mesh tested in the sensitivity study

The simplification of the 2D simulation results in a total mass flow rate of $0.041 \mathrm{~kg} / \mathrm{s}$. Due to the computational expense of having millions of particles in a simulation the mass flow rate of $0.041 \mathrm{~kg} / \mathrm{s}$ has been separated into two mass flow rates, $0.0369 \mathrm{~kg} / \mathrm{s}$ for the coarse material and $0.0041 \mathrm{~kg} / \mathrm{s}$ for the fines. Although the fines make up $0.0041 \mathrm{~kg} / \mathrm{s}$ of the mass flow rate in the experiments, this was modified to a mass flow rate of $0.00041 \mathrm{~kg} / \mathrm{s}$ in order to decrease the number of particles in the simulation. This can be justified by the main aim of this case study being a qualitative investigation.

The simulation used a transient pressure based solver with the coupled pressure - velocity scheme with gravity set to $9.81 \mathrm{~m} / \mathrm{s}^{2}$ in the negative $\mathrm{Y}$ direction. Air viscosity was calculated using the K-Epsilon Realisable model with Standard Wall Functions, the discrete phase was used to track particles with unsteady particle tracking with each fluid time step. Two-way turbulence coupling was also used to ensure the particles would influence the air and generate the velocity profile inside the silo. The simulation used a time step size of 0.001 seconds and 35 iterations per time step.

After investigating different parcel release methods it was found that the "standard" method did not show the same results as observed in the experiments and that a better result was 
obtained by setting the release method to "constant number of particles" (see Figure 3). Therefore, the discrete phase modelling was set to contain 1 particle per parcel this then forces the simulation to behave as a traditional DEM simulation in that a single particle is tracked rather than a parcel of particles that represents a fraction of the total mass flow released in a time step.

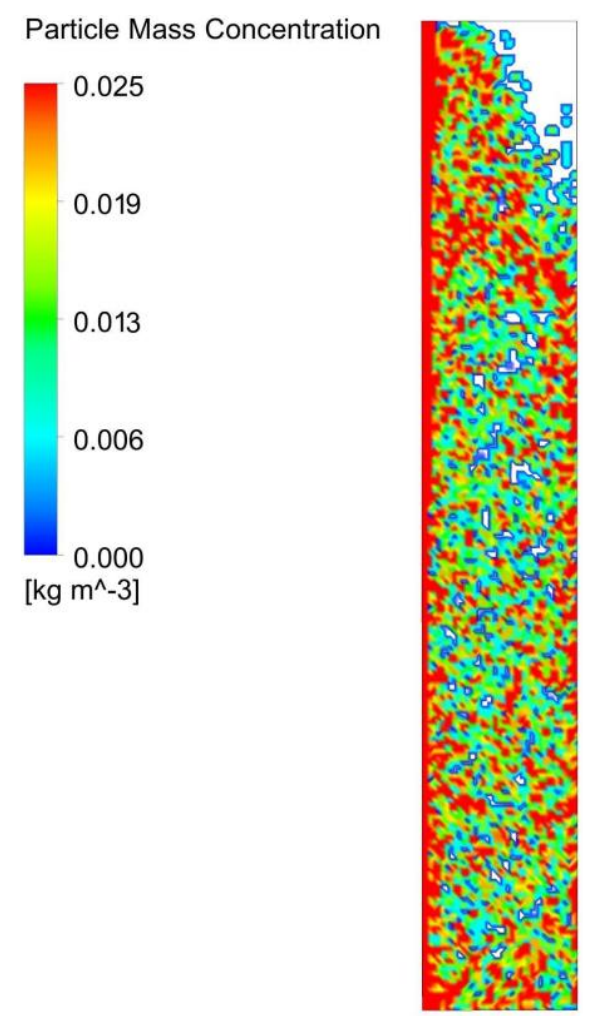

Figure 12: Particle Concentration with Standard Particle Release Method

Table 5 outlines the settings used for the particle injections in the simulation. Further, as seen in earlier sections of this paper, the material is similar to a flat disk and as such a shape factor of 0.2 has been used. This shape factor was determined after consulting the work conducted by (Haider \& Levenspiel 1989) which is the method that Fluent uses to determine the particle terminal velocity and drag coefficient. 
Table 5: Injection Settings

\begin{tabular}{|l|c|c|}
\hline Particle Setting & $\begin{array}{c}\text { Coarse Material } \\
\text { (Uniform Distribution) }\end{array}$ & $\begin{array}{c}\text { Fine Material } \\
\text { (Rosin Rammler Distribution) }\end{array}$ \\
\hline Start time [s] & 0 & 2 \\
\hline End Time [s] & 20 & 0.00041 \\
\hline Mass Flow Rate [kg/s] & 0.0369 & - \\
\hline Diameter [um] & 3950 & 63 \\
\hline Minimum Diameter [um] & - & 355 \\
\hline Maximum Diameter [um] & - & 134.3 \\
\hline Mean Diameter [um] & - & 1.93 \\
\hline Spread Factor & - & 10 \\
\hline Number of Diameters & None & $\begin{array}{c}\text { Stochastic; Discrete Random } \\
\text { Walk Model; Random Eddy } \\
\text { Life Time }\end{array}$ \\
\hline Turbulent Dispersion & & 0.2 \\
\hline Shape Factor & 0.2 & \\
\hline
\end{tabular}

\section{Results and discussion}

\section{Dust concentration measurements using optical methods}

Knowing that the lower explosion limit of wood dust is around $300 \mathrm{~g} / \mathrm{m}^{3}$ concentrations of fines in the silo were mapped to identify areas with concentrations close to this limit. Starting from the centre line and moving towards the silo wall, three different dust concentration contour maps were generated. The first map showed fines carried away by circulating air currents to form a re-circulating region close the centrally fed particle jet. This finding is consistent with (Wypych et al. 2005) and (Wang et al. 2016) who identified a high recirculating region near a falling particle stream which accelerates the migrations of fines into the surrounding air. 


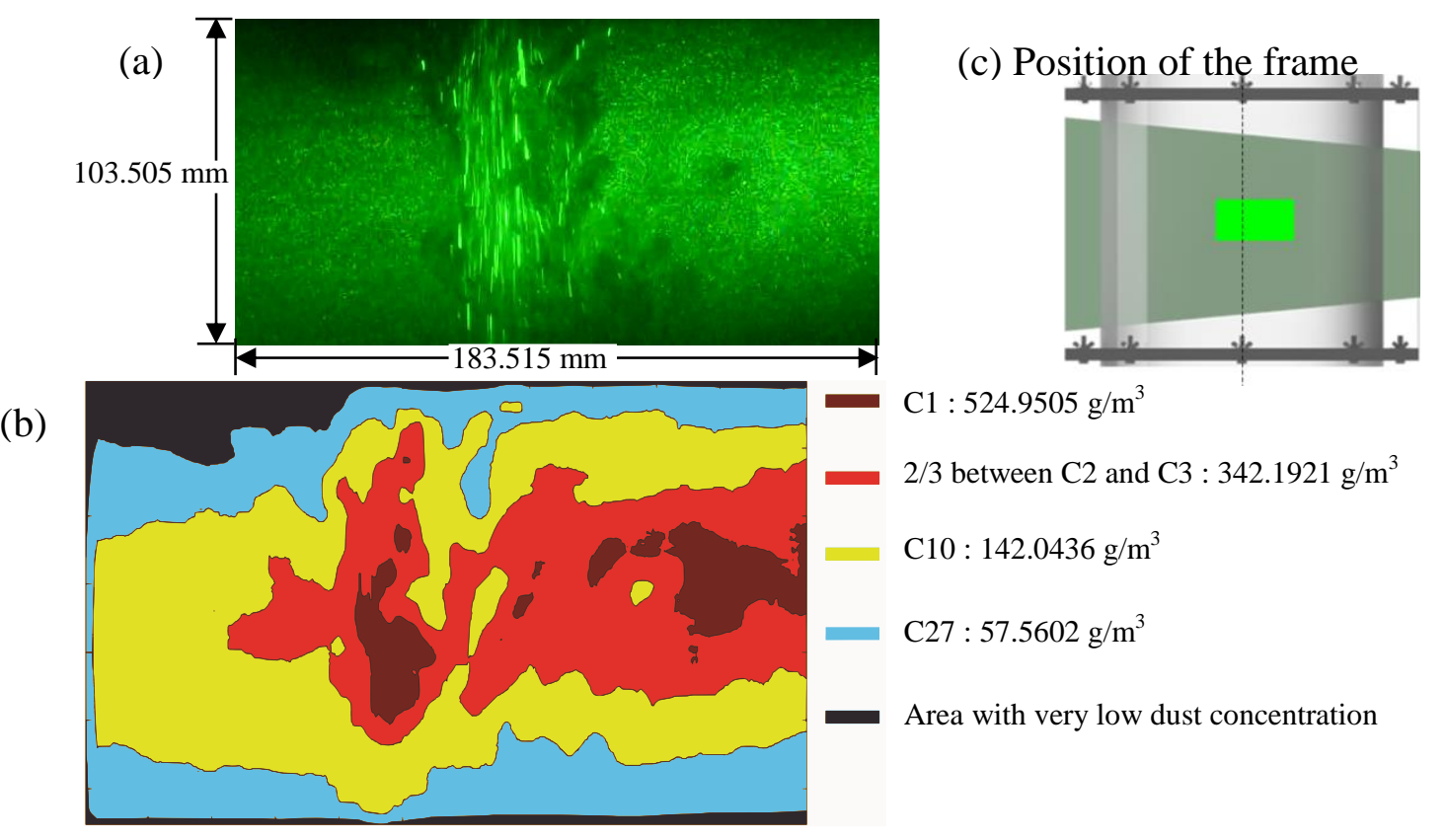

Figure 13: Dust concentration(s) near the particle jet at a particle feeding rate of $81.87 \mathrm{~g} / \mathrm{s}$; (a) Cropped image from averaged frame of the video footage. (b) Contour map of dust concentration(s) near the particle jet. (c) Position of image which cropped from the average frame.

The dust concentration contour map shown in Figure 13 depicts another area of high dust accumulation of around $440 \mathrm{~g} / \mathrm{m}^{3}$ close to the wall. The particles observed in this area are mostly fines, the larger particles dropped out from the airstream already and settled on the heap.

The upward moving air near the silo wall gradually reduces its velocity with entrained particles gradually settling to the bottom (Rani et al. 2015). These settling particles are continuously charged by fresh fines from the main falling stream. (Zhang et al. 2013) showed that the particle charges increase with decreasing particle diameter e.g. wood pellets of around $212 \mu \mathrm{m}$ showed a specific charge density of $-24.77 \mu \mathrm{C} / \mathrm{kg}$. Wood particles are charged even more when coming in contact with the silo wall (e.g. steel silos for storing wood pellets) as the work function is higher between particles and a steel plate (Hussain et al. 2013). This highly, negatively, charged particles form a solid like network with similar distances between them and can create a potentially explosive fuel like mixture in the presence of a spark or other ignition sources. 


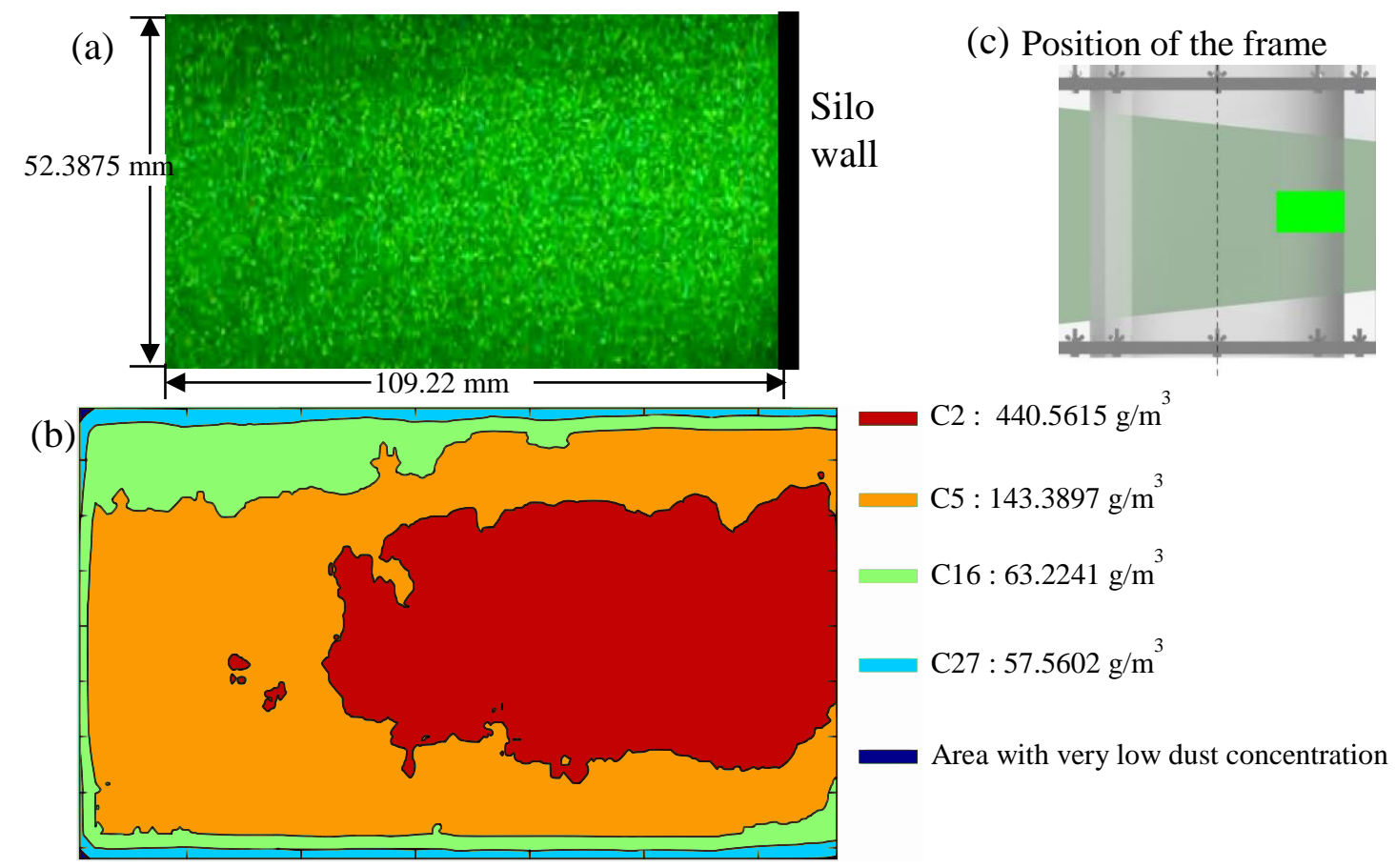

Figure 14: Dust concentration(s) near the silo wall (a) Cropped image from averaged frame of the video footage. (b) Contour map of dust concentration(s) near the particle jet. (c) Position of image which cropped from the average frame.

Figure 14 depicts a dust concentration contour map between the silo centre line and the silo wall which clearly shows less particles in the frame than in the other two dust concentration contour maps.

The obtained dust concentration distribution in the experimental silo was then compared with CFD results by (Rani et al. 2015). Since the materials used were different and the silos had different dimensions only qualitative information can be derived from this comparison. Rani et al. 2015 simulated the dust concentration distribution in a cylindrical silo of $5 \mathrm{~m} \times 1.6 \mathrm{~m}$ (height $\mathrm{x}$ diameter) and obtained dust concentration near the centrally falling particle stream of around $600 \mathrm{~g} / \mathrm{m}^{3}$ and near the wall of around $200 \mathrm{~g} / \mathrm{m}^{3}$. In this study the dust concentration measured at the centre line of the silo was about $525 \mathrm{~g} / \mathrm{m}^{3}$ and near the silo wall of about 440 $\mathrm{g} / \mathrm{m}^{3}$. Dust concentrations near the silo centre line were quite similar but those close to the wall were a factor of two higher. 
The prevention of dust explosions in industrial silos can be achieved by minimising/ eliminating the formation of dust clouds that exceed the lower explosion limit (LEL) (Rani et al. 2015).

(b)

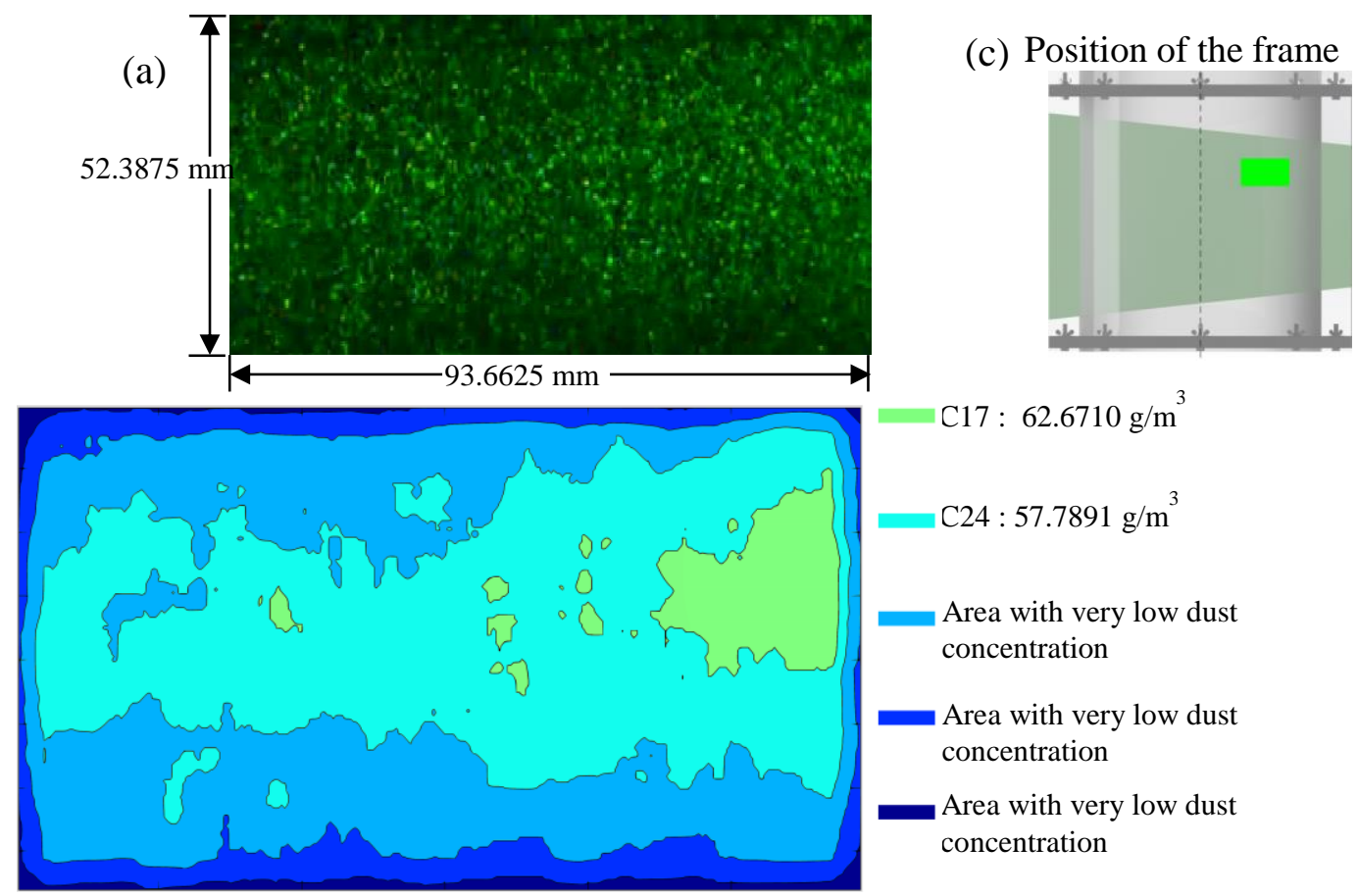

Figure 15: Dust concentration of an area with less particles. (a) Cropped image from averaged frame of the video footage. (b) Contour map of dust concentration(s) near the particle jet. (c) Position of image which cropped from the average frame.

The formation of dust clouds can be suppressed by installing an "Anti-segregation tube (AST)" (Dyrøy et al. 2001) into the biomass storage silo. ASTs are used successfully in alumina storage silos in Norway.

\section{Verification of optical methods using a coupled CFD-DEM approach}

After comparing the concentrations, it appears that there is a good qualitative agreement between the CFD and the optical method. In particular, the concentration at the silo wall presents the same pattern observed in the experiments with a higher concentration at the wall with progressively lower concentrations moving towards the core stream.

Although the concentration patterns appear similar, the concentration values themselves are a factor of 100 lower when compared to the optical results. The scaling of the mass flow rate of fines entering the silo has led to this lower observed particle concentration; with increased particles in the simulation, the concentrations would approach those derived from the optical method. 
From this qualitative investigation, it has been determined that the particle concentrations are dependent on the particle drag coefficient and terminal velocity. The shape factor directly influences these key parameters; by changing the particle shape factor, the drag coefficient and terminal velocity can be adjusted. This adjustment can be lead to a lower velocity required to suspend particles, which will determine where the concentration of dust occurs. Additionally, the air hydrodynamics are a key area of interest when investigating where the dust concentrations will form; the concentration location can be predicted from the terminal velocity of the particle and the air velocity at a particular location.

(a)

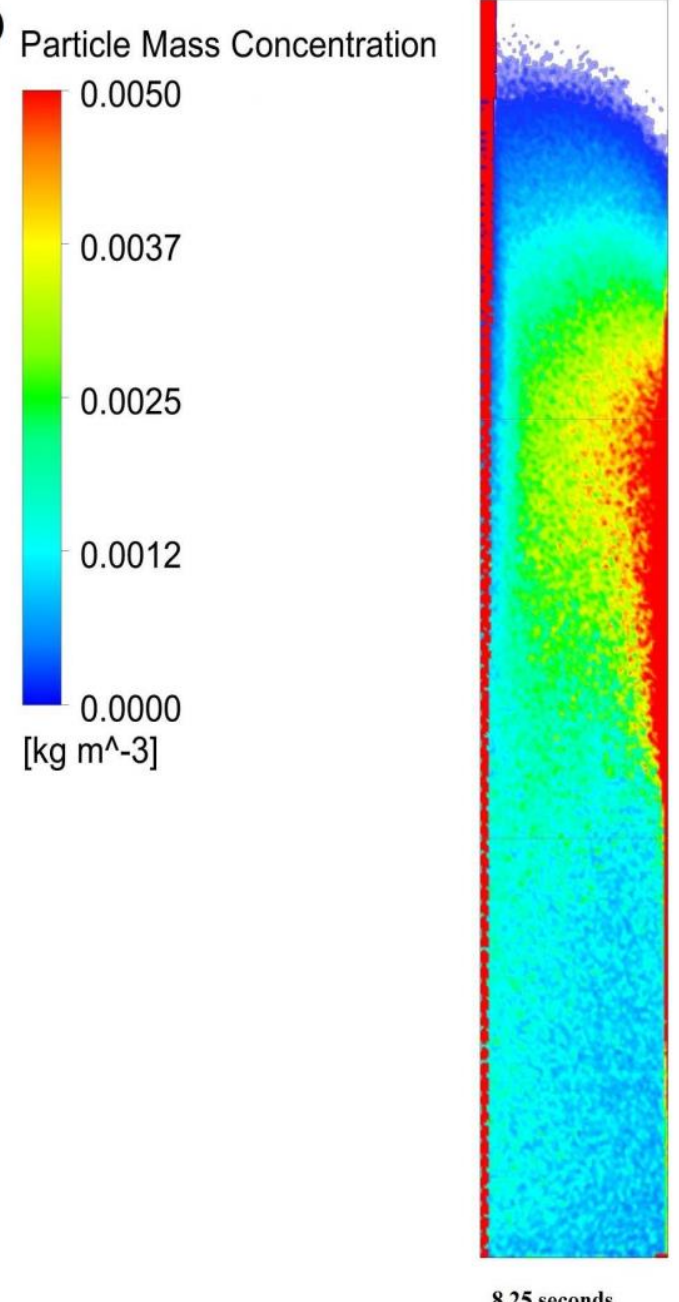

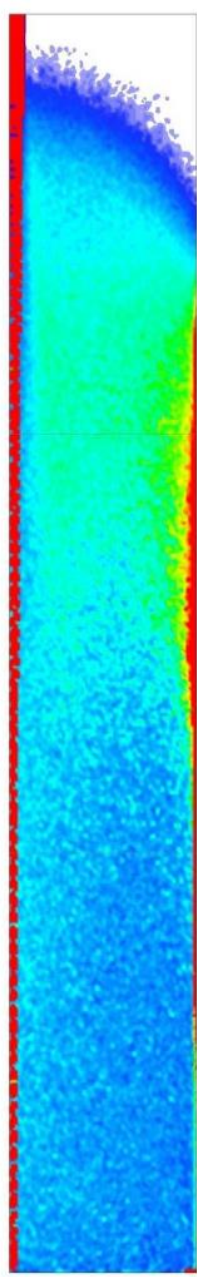

(b) Velocity

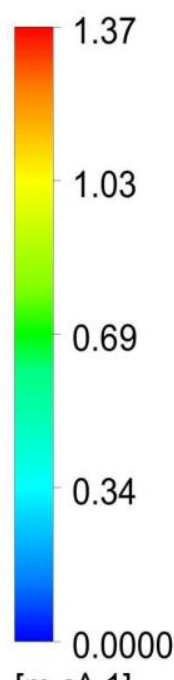

$\left[\mathrm{m} \mathrm{s}^{\wedge}-1\right]$

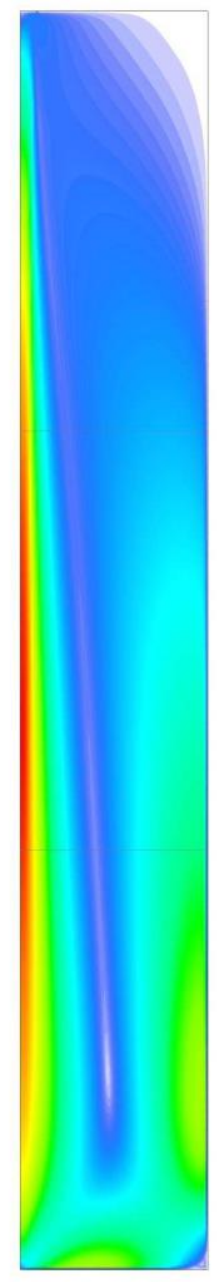

15 seconds

Figure 16: (a) Particle Concentration Renders at 8.25 seconds and 15 seconds (b) Velocity profile 


\section{Conclusions}

Dust explosions during the handling and storing of biomass such as wood pellet present a high risk to plant operators and can cause serious structural damages. The ability to evaluate and manage the risks of dust explosions in large scale biomass storage facilities largely depends on a profound understanding of dust mobility in the vessel. The dust mobility can be studied using simulation approaches such as CFD which requires validation data from existing installations or experimental data.

This paper proposes an analytical method to create dust concentration contour maps which give a clear indication how the concentration is distributed in the silo. To obtain concentration contour maps, wood pellets with different particle sizes and wood dust were fed centrally into an experimental silo. A camera system captured the particle dynamics and the video footage was analysed using a Matlab® programme. The obtained dust concentration contour maps showed a high dust concentration near the silo centre line (falling particle jet) and the silo wall. Although the concentration patterns appear similar in the simulation and experiments, the concentration values in the simulation are a factor of 100 lower when compared to the optical results. The values near the silo wall were more realistic with the newly proposed optical method than the simulation. This can be partly explained by the fact that this method captures better the particles dynamics near the silo wall. Particle concentrations of $440 \mathrm{~g} / \mathrm{m}^{3}$ were measured near the silo wall which represents a high dust explosion risk with the presence of an ignition source. The dust settles near the silo wall and because of particle-particle and particle-wall interactions the fines are continuously charged. These charged particles could create a solid like network between the particles which creates a stable atmosphere fuel mixture leading to an even higher dust explosion risk. From this qualitative investigation, it has been determined that the particle concentrations are dependent on the particle drag coefficient and terminal velocity. The values obtained for terminal velocity were similar between experiments and simulations. Further developments of the CFD model for obtaining quantitative results will include the introduction of an experimentally based particle shape factor and running the CFD simulation on a higher capacity computer. This would allow for a greater number of particles to be used in the simulation. A large-scale investigation should be undertaken to ensure that the simulation is scalable. 


\section{Acknowledgement:}

With great gratitude we would like to thank Gexcon AS - DSEAR, Fire and Explosion Consultants (www.gexcon.com/) and the University of Greenwich for funding this research and the research support team at The Wolfson Centre.

\section{References:}

Allen, T., 2003. Powder Sampling and Particle Size Determination, Elsevier. Available at: https://books.google.com/books?hl=en\&lr=\&id=5NgqTf9L63kC\&pgis=1 [Accessed April 27, 2016].

Scott G. D., Hinze, P.C., Hansen, O.R., Wingerden, K., 2011. Does your facility have a dust problem: Methods for evaluating dust explosion hazards. Journal of Loss Prevention in the Process Industries, 24(6), pp.837-846.

Dyrøy, A., 2006. Quantification and mitigation of segregation in the handling of alumina in aluminium production, internal report.

Frank, W.L., 2004. Dust explosion prevention and the critical importance of housekeeping. Process Safety Progress, 23(3), pp.175-184. Available at: http://www.scopus.com/inward/record.url?eid=2-s2.010244267547\&partnerID=tZOtx3y1 [Accessed April 27, 2016].

Gouesbet, G., Gréhan, G., 2015. Laser-based optical measurement techniques of discrete particles: A review [invited keynote]. International Journal of Multiphase Flow, 72, pp.288-297.

Haider, A. \& Levenspiel, O., 1989. Drag coefficient and terminal velocity of spherical and nonspherical particles. Powder Technology, 58(1), pp.63-70. Available at: http://www.sciencedirect.com/science/article/pii/0032591089800087 [Accessed May 27, 2016].

Hussain, T. et al., 2013. A novel sensing technique for measurement of magnitude and polarity of electrostatic charge distribution across individual particles. International journal of pharmaceutics, 441(1-2), pp.781-789. Available at: 
http://www.sciencedirect.com/science/article/pii/S0378517312009428.

Klippel, A., Schmidt, M., Muecke, O., Krause, U., 2014. Dust concentration measurements during filling of a silo and CFD modeling of filling processes regarding exceeding the lower explosion limit. Journal of Loss Prevention in the Process Industries, 29, pp.122137. Available at: http://www.sciencedirect.com/science/article/pii/S0950423014000291.

Krueger, B., Wirtz, S., Scherer, V., 2015. Measurement of drag coefficients of non-spherical particles with a camera-based method. Powder Technology, 278, pp.157-170.

Oveisi, E., Lau, A., Sokhansanj, S., Lim, C.J., Bi, X., Larsson, S., Melin, S., 2013. Breakage behavior of wood pellets due to free fall. Powder Technology, 235, pp.493-499.

Rani, S.I., Aziz, B.A. \& Gimbun, J., 2015. Analysis of dust distribution in silo during axial filling using computational fluid dynamics: Assessment on dust explosion likelihood. Process Safety and Environmental Protection, 96, pp.14-21.

Réthoré, J., Morestin, F., Lafarge, L., Valverde, P., 2014. 3D displacement measurements using a single camera. Optics and Lasers in Engineering, 57, pp.20-27.

U.S. CSB, 2010. Investigation Report, COMBUSTIBLE DUST HAZARD STUDY. $U . S$. Chemical Safety and Hazard Investigation Board. Available at: http://www.csb.gov/assets/1/19/dust_final_report_website_11-17-06.pdf.

Wang,Y., Ren X., Zhao J., Chu Z., Cao Y., Yang Y., Duan M., Fan H., Qu X, 2016. Experimental study of flow regimes and dust emission in a free falling particle stream. Powder Technology, 292, pp.14-22.

Wypych, P., Cook, D., Cooper, P., 2005. Controlling dust emissions and explosion hazards in powder handling plants. Chemical Engineering and Processing: Process Intensification, 44(2), pp.323-326.

Zhang, L., Hou, J., Bi, X., 2013. Triboelectric charging behavior of wood particles during pellet handling processes. Journal of Loss Prevention in the Process Industries, 26(6), pp.1328-1334. 